International Journal of

Health, Medicine and

Nursing Practice

(IJHMNP)

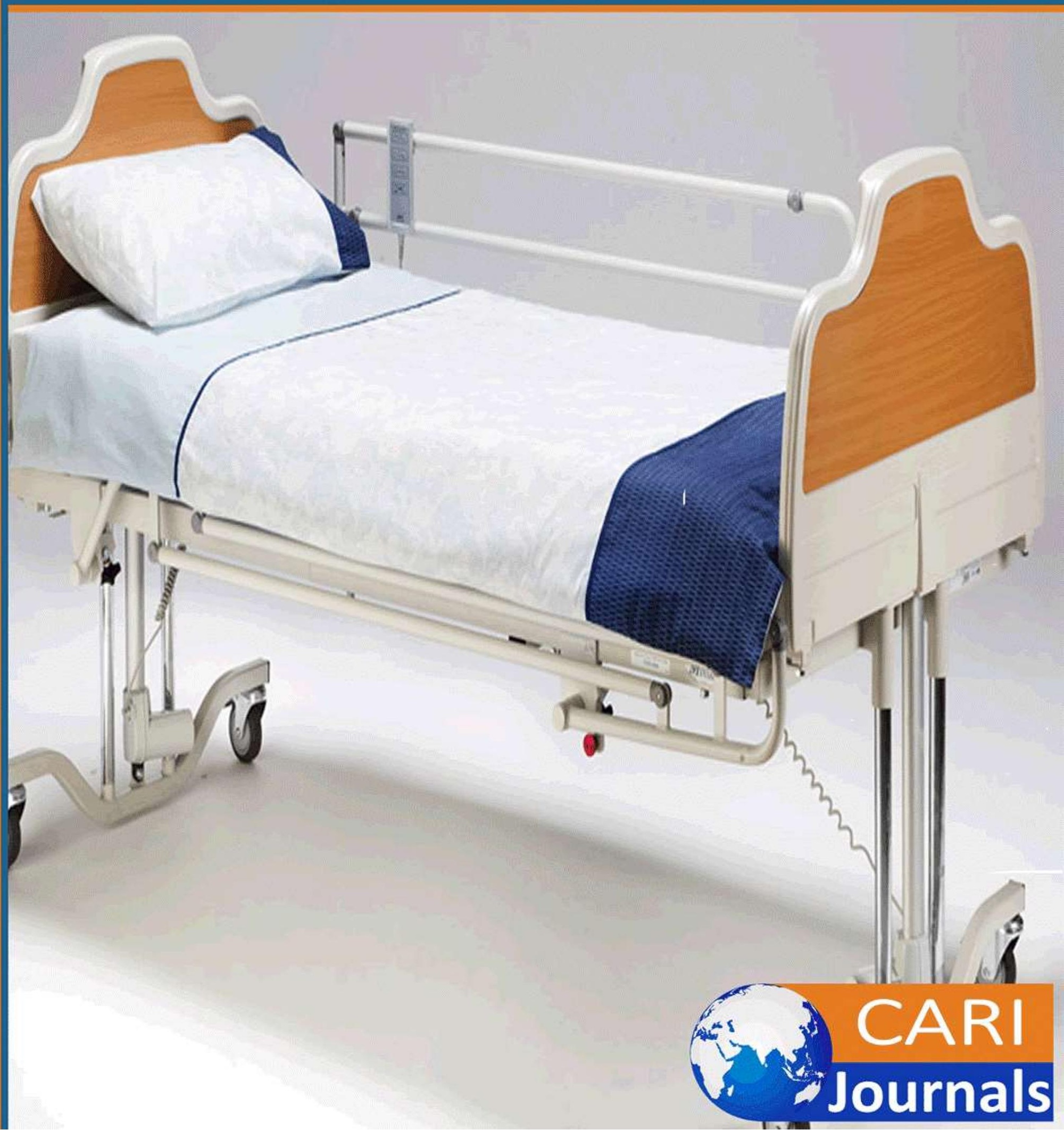




\title{
FAMILY PLANNING KNOWLEDGE, ATTITUDE AND PRACTICE AMONG WOMEN OF REPRODUCTIVE AGE IN NIMULE PAYAM, SOUTH SUDAN
}

\author{
1*Andrew Drici \\ Student, School of Health Sciences, Mountains of the Moon University, P.O. Box 837, Fort \\ Portal, Uganda \\ *Corresponding Author's E-mail: drici.andrew@gmail.com
}

${ }^{2}$ Isaac Eremugo

Post Graduate Student, College of Agricultural and Environmental Sciences, Makerere University, P.O. Box 7062, Kampala Uganda.

${ }^{3}$ Dr. Sarah Akello

Lecturer, College of Agricultural and Environmental Sciences, Makerere University, P.O. Box 7062, Kampala Uganda.

${ }^{4}$ Maureen Andinda

Lecturer, School of Health Sciences, Mountains of the Moon University, P.O. Box 837, Fort Portal, Uganda

\begin{abstract}
Purpose: The purpose of this study was to examine family planning Knowledge, Attitude and Practice (KAP) among women of reproductive age in Nimule Payam, South Sudan.

Method: The study used a descriptive cross-sectional design and quantitative approach to explore family planning knowledge, attitude and practice among women of reproductive age in Nimule Payam. The study population consisted of 6,621 women of reproductive age in the Bomas of Anzara (1,930), Jalei(,1521), Olikwi $(1,536)$ and Nimule Central $(1,634)$. A sample size of 342 was determined from the population using the formulae of Leslie. Stratified simple random sampling was employed through a researcher administered structured questionnaire to collect data from the respondents. The data was cleaned, coded and analyzed using EPI-INFO version 7 to generate descriptive statistics and the results were presented in tables.

Results: The study revealed that women of reproductive age in Nimule Payam had high 273 (79.82\%) level of family planning knowledge, good $233(68 \%)$ family planning practices and positive attitude towards family planning. The positive attitude towards family planning was because majority $270(78.97 \%)$ believed family planning was safe to use, could not cause infertility $252(73.82 \%)$, cancer $264(76.93 \%)$ and future abortion 251 (73.36\%). The respondents also generally agreed that $319(93.07 \%)$ family planning could prevent unwanted pregnancy. However, the majority of the respondents acknowledged that the practice of family planning was against their God/Allah 268 (78.31\%) and culture $229(67.03 \%)$.

Unique contribution to theory, practice and policy: The study found that women of reproductive age in Nimule Payam had a high level of family planning knowledge, a fairly positive attitude with a moderate number practicing family planning methods. Increased sensitization of the respondents and their partners on family planning is required to improve their attitude and practice. Future studies should focus on the factors influencing the
\end{abstract}


International Journal of Health, Medicine and Nursing Practice ISSN 2710-1150 (Online)

Vol.3, Issue No.4, pp $25-41,2021$

Knowledge, Attitude and Practice of family planning methods among women of reproductive age in Nimule Payam.

Key words: Knowledge, Attitude, Practice, Family Planning, South Sudan

\subsection{INTRODUCTION}

\subsection{Background to the study}

Family planning are services, policies, information, attitudes, practices and commodities, including contraceptives, that give women and men the ability to avoid unintended pregnancy and choose whether to have a child or not (Starbird et al., 2016). This is contrary to the thinking in the last three or so decades producing as many children as possible was the order of the day (Kane et al., 2016). This has resulted in increased attempts to limit and manage their birthrates (Naidu et al., 2017; Obwoya et al., 2018; Sensoy et al., 2018).

According to the United Nations [UN] (2015), family planning averts an estimated 82 million unwanted pregnancies, 25 million unsafe abortions, and 125,000 maternal deaths annually. Unsafe abortion alone contributes to $5 \%-18 \%$ of maternal mortality in a year (Heil et al., 2019). Family planning is now considered a human right and investing in family planning has been described as a development's ' best buy." because of the benefits it has on the individuals, the societies and the country as a whole (Tolefac et al., 2018). It contributes to the attainment of the Sustainable Development Goals (SDGs) across the 5 SDG whose themes focuses on people, planet, prosperity, peace, and partnership in addition to poverty reduction (Starbird et al., 2016). Family planning has resulted in the reduction of; maternal mortality ratio (MMR), unwanted pregnancy, unsafe abortion, infant mortality, fertility rate and prevention of the transmission of Sexually Transmitted Diseases (Heil et al., 2019; Sarnquist et al., 2008).

Furthermore, there is an increased trend of contraceptive use globally due to high family planning knowledge among women of reproductive age. An estimated 650 million (62\%) of married women of reproductive age in 2018 were using contraceptives worldwide (Aliyu, 2018). The use of contraceptives in America, Latin America and Caribbean, Europe, Asia and Africa were $74 \%, 74 \%, 70 \%, 64 \%$ and $36 \%$, respectively. The practice of family planning is at its optimum in Norway $(88 \%)$ while South Sudan $(4 \%)$ ranks bottom in the World (Population Reference Bureau, 2019; United Nations [UN], 2017). South Sudan has, poor family planning services hence resulting into an alarming maternal mortality ratio of 789 per 100,000 live births, the highest in the world (Kane et al. 2016). The low practice of family planning methods in South Sudan can be attributed to many factors such as the long period of civil war that has destroyed the social service infrastructures.

The government of South Sudan has earmarked on health sector reforms as one of the key postindependence priorities (Government of Southern Sudan [GOSS], 2011).Fortunately, the health sector including family planning services has received support from both the government and international donors. Recent study by Obwoya et al. (2018) on factors influencing contraceptive use among women of reproductive age in Juba City of South Sudan revealed a bit of improvement especially in the area of knowledge while practice continued to lag behind. Another study by Kane et al. (2016) focused on social norms and family planning decisions among the Fertit Community in Northern Bahr el Ghazal State of South Sudan, where it revealed that women of reproductive age among the Fertit community were expected to have as many children as possible. However, there is limited information on the Knowledge, 
Attitude and Practices (KAPs) of family planning among women of reproductive age in the rural areas of South Sudan such as Nimule Payam and Eastern Equatoria. Nimule Payam has received one of the highest numbers of Internally Displaced Persons (IDPs) mainly from Bor in Jonglei State and other counties within Eastern Equatoria State which resulted into widening the existing health gap. The government in partnership with Non-Governmental Organizations (NGOs) have targeted Nimule Payam for increased provision of family planning services through delivery of free family planning inputs and education at Nimule Hospital, in addition to conducting education outreach programs through Village Health Teams (VHTs).

This study is anchored on the Theory of Change coined by Weiss (1995), as "a theory of how and why an initiative works." Theory of Change shows the pathways through which change is expected to occur and defines how project inputs are transformed into results (Silva et al., 2015). This Theory has become one of the most widely used theories in project interventions although it has been criticized because it simplifies change by representing it as a linear pathway which is not always the case in real life (Armitage et al., 2019; de Silva et al., 2014; Reinholz \& Andrews, 2020).

\subsection{Problem Statement}

Although, the government of South Sudan in partnership with Non-Governmental Organizations (NGOs) have been providing free family planning services in Nimule Hospital since independence in 2011, Contraceptive Prevalence Rate (CPR) in Nimule Payam stands at $1.5 \%$, below the national average of $4.7 \%$ ((USAID, 2018; Kane et al., 2016). Whereas information on the Maternal Mortality Ratio (MMR) for the whole of the Payam is scanty, studies predict it to be higher than the national MMR of 789 per 100,000 live births (Kane et al., 2016). This is due to high number of Internally Displaced Persons (IDPs) and insecurity in some parts of the Payam that acted as barriers to accessing family planning services at the hospital.

Previous studies on family planning in South Sudan focused on factors influencing contraceptive use among women of reproductive age in Juba City, Central Equatorial State (Obwoya et al., 2018), social norms and family planning decision making among the Fertit community in Bahr el Ghazal State (Kane et al., 2016) and barriers to promoting maternal and child health in South Sudan (Mugo et al., 2015); According to Tolefac et al. (2018), Knowledge, Attitude and Practices (KAPs) of family planning methods among women of reproductive age are known to reduce unwanted pregnancies, unsafe abortion and maternal mortality ratio. To increase the Knowledge, Attitude and Practice of family planning methods among women of reproductive age in Nimule Payam, the government in partnership with NonGovernmental Organizations (NGOs) has continued to provide free family planning inputs and introduced community outreach programs. It is not clear how the efforts of the government of South Sudan and its development partners have impacted the Knowledge, Attitude and Practices (KAPs) of family planning methods among women of reproductive age in Nimule Payam, yet this is important for informed decision making. This study addresses this knowledge gap.

\subsection{Purpose of the study}

To examine family planning Knowledge, Attitudes and Practices among women of reproductive age in Nimule Payam, South Sudan.

\subsection{Specific Objectives}


1) To determine the knowledge level of women of reproductive age in relation to family planning in Nimule Payam.

2) To assess the attitude of women of reproductive age in relation to family planning in Nimule Payam.

3) To assess the practices of women of reproductive age in relation to family planning in Nimule Payam.

\subsection{Research questions}

1) What is the knowledge level of women of reproductive age in relation to family planning in Nimule Payam?

2) What is the attitude of women of reproductive age in relation to family planning in Nimule Payam?

3) What are the practices of women of reproductive age in relation to family planning in Nimule Payam?

\subsection{RESEARCH METHODS}

The study employed a descriptive cross-sectional design, quantitative approach using survey of primary data collection. The study population consisted of 6,621 women of reproductive age drawn from the Bomas of Anzara (1930), Jalei (1521), Olikwi (1536) and Nimule Central (1634) (Shelter NFI Cluster South Sudan, 2017). A sample size of 342 was determined from the population using the formulae of Leslie (1965) at 95\% confidence level, 5\% margin of error and $10 \%$ non-response rate (Nsubuga et al., 2016). Stratified sampling was employed by first determining sample size proportionate to the number of women of reproductive age in each Boma. This was followed by simple random sampling within each Boma. Data was collected from all the 342 targeted respondents using a researcher administered structured questionnaire. The collected data was cleaned, coded and analyzed for descriptive statistics (frequency and percentages) using EPI-INFO version 7. Before the data collection exercise, the questionnaire was revised by experts in the field to ensure its validity. The questionnaire was also pre-tested by administering it to $35(10 \%)$ women of reproductive age in the adjacent Mugali Payam to ensure its reliability.

Respondents' overall knowledge level on family planning method was assessed on a score of 0-10 based on 10 family planning related questions. A correctly answered question corresponded to a score of one while an incorrect answer was given a score of zero. The respondents who attained an overall scored of 7 (70\%) and above were rated as having high family planning knowledge (Kasa et al., 2018). The respondents' practice of family planning was assessed based on the summative score of the family planning related questions. Women who scored $60 \%$ and above were considered as having better family planning practices (Hamed et al., 2018; Kassa et al., 2014).

Respondents' attitudes were rated on 4- Likert scales based on their levels of agreement; Strongly Agreed (SA), Agreed (A), Disagreed (D) and Strongly Disagreed (SD). Participants who Strongly Agreed and Agreed with statements that supported family planning were considered to have positive attitude towards family planning methods. While, those respondents who Strongly Disagreed and Disagreed were considered to have a negative attitude towards family planning methods. A score of one was given to all responses with Strongly Agreed and Agreed and a score of zero for Strongly Disagreed and Disagreed. Based on the statements assessing attitude, women who scored $60 \%$ and above were considered as having 
International Journal of Health, Medicine and Nursing Practice ISSN 2710-1150 (Online)

positive family planning attitude (Kassa et al., 2014). Results from the descriptive statistics were presented in bar graph and tables.

\subsection{RESULTS}

\subsection{Socio-demographic characteristics of the study participants}

Table 1 presents the socio-demographic characteristics of the 342 women of reproductive age (15-49) who were surveyed for knowledge, attitude and practice of family planning methods in Nimule Payam,

Table 1. The socio-demographic characteristics of the study participants, Nimule Payam $(n=342)$

\begin{tabular}{|c|c|c|}
\hline Variables & Frequency & Percentage $(\%)$ \\
\hline \multicolumn{3}{|l|}{ Age } \\
\hline $15-19$ & 52 & 15.33 \\
\hline $20-24$ & 62 & 18.25 \\
\hline $25-29$ & 65 & 18.98 \\
\hline $30-34$ & 72 & 21.17 \\
\hline $35-39$ & 43 & 12.41 \\
\hline $40-44$ & 33 & 9.49 \\
\hline $45-49$ & 15 & 4.38 \\
\hline \multicolumn{3}{|l|}{ Marital Status } \\
\hline Cohabiting & 7 & 2.17 \\
\hline Divorced & 25 & 7.25 \\
\hline Married & 202 & 59.06 \\
\hline Single & 104 & 30.43 \\
\hline Widow & 4 & 1.09 \\
\hline \multicolumn{3}{|l|}{ Numbers of Children } \\
\hline $0-5$ & 282 & 82.30 \\
\hline $6-10$ & 53 & 15.64 \\
\hline $10-15$ & 7 & 2.06 \\
\hline \multicolumn{3}{|l|}{ Religion } \\
\hline Christian & 273 & 79.86 \\
\hline Muslim & 63 & 18.35 \\
\hline \multicolumn{3}{|l|}{ Others (Traditional believers \& } \\
\hline Pagans) & 6 & 1.80 \\
\hline \multicolumn{3}{|l|}{ Educational Level } \\
\hline No Formal Education & 62 & 17.99 \\
\hline Primary & 52 & 15.47 \\
\hline Secondary & 179 & 52.16 \\
\hline Tertiary & 49 & 14.39 \\
\hline \multicolumn{3}{|l|}{ Occupation } \\
\hline Business & 119 & 34.77 \\
\hline Causal worker & 32 & 9.32 \\
\hline Others (Farmers) & 18 & 5.38 \\
\hline Salaried (Private \& Public sector) & 44 & 12.90 \\
\hline
\end{tabular}


International Journal of Health, Medicine and Nursing Practice ISSN 2710-1150 (Online)

Vol.3, Issue No.4, pp 25 - 41, 2021

\begin{tabular}{lll}
\hline Student & 79 & 22.94 \\
Unemployed (House wives) & 50 & 14.70 \\
\hline
\end{tabular}

Results in Table 1 revealed that more than half $99(58.40 \%)$ of the respondents were young women aged 20 - 34 years, followed by the age group of 15-19, represented by $52(15.33 \%)$ respondents. Most $202(59.06 \%)$ of the women of reproductive age in Nimule Payam were married. Majority $282(82.30 \%)$ of the women of reproductive age in Nimule Payam had 0-5 children. The main religion of the respondents were 273 (79.86\%) Christianity and 63(18.35\%) Muslims. Half 179 (52.16) of the women of reproductive age in Nimule Payam finished secondary level of education, the second majority $62(17.99 \%)$ had no formal education while the third majority $52(15.47 \%)$ finished primary level of education.

The main occupation of the women of reproductive age in Nimule Payam was $119(34.77 \%)$ Business, 79 (22.94\%) students and 50 (14.70\%) housewives. Very few 44 (12.90\%) women of reproductive age in the Payam were in formal employment. The finding implies that the occupation of the majority of the women of reproductive age in Nimule Payam were mainly business. This was because insecurity could not allow women to go to farmlands located outside the established settlement. As such majority had to settle to do small businesses in the markets locally referred to as "awara". Awara involves the women in Nimule Payam crossing to the Elegu border town of Uganda to items such as vegetables for sell in Nimule Payam, South Sudan.

\subsection{Knowledge of the respondents on family planning}

The knowledge of the women of reproductive in relation to family planning in Nimule Payam was assessed based on scores of their responses to family planning method related questions. Table 2 presents the knowledge of women of reproductive age in Nimule Payam on family planning methods.

Table 2. Knowledge of the respondents on family planning in Nimule Payam $(n=342)$.

\begin{tabular}{lcc}
\hline Question/Statements & Frequency & Percentage (\%) \\
\hline Ever heard about family planning & & \\
Yes & 301 & 88.00 \\
No & 41 & 12.00 \\
Where did you hear about family planning & & \\
Community Meetings & 25 & 6.65 \\
Friends & 43 & 11.44 \\
Health Facility & 232 & 61.7 \\
Media & 14 & 3.72 \\
Outreach workers & 52 & 13.83 \\
Others (Church/Mosque, Group Meeting)) & 10 & 2.66 \\
Which family planning method do you know? & & \\
Condoms & 145 & 18.59 \\
Oral pills & 178 & 22.82 \\
Injecta plan & 151 & 19.36 \\
Implants & 100 & 12.82 \\
IUD & 61 & 7.82 \\
\hline
\end{tabular}


International Journal of Health, Medicine and Nursing Practice ISSN 2710-1150 (Online)

Vol.3, Issue No.4, pp 25 - 41, 2021

www.carijournals.org

\begin{tabular}{|c|c|c|}
\hline Lactational Amenorrhea & 61 & 7.82 \\
\hline Sterilization & 39 & 5.00 \\
\hline Withdrawal & 45 & 5.77 \\
\hline \multicolumn{3}{|l|}{ Do you know where to get contraceptives? } \\
\hline Yes & 267 & 78.00 \\
\hline No & 75 & 22.00 \\
\hline \multicolumn{3}{|l|}{ Importance of family planning } \\
\hline Prevent Pregnancy & 164 & 46.59 \\
\hline Prevent STDs/STIs & 118 & 33.52 \\
\hline Space Children & 46 & 13.07 \\
\hline Don’t Know & 24 & 6.82 \\
\hline \multicolumn{3}{|l|}{ Responsible person for family planning } \\
\hline Women & 110 & 32.00 \\
\hline Men & 3 & 1.00 \\
\hline Both Women \& Men & 229 & 67.00 \\
\hline \multicolumn{3}{|l|}{ Users of family planning } \\
\hline Sexually Active Men \& Women & 182 & 53.10 \\
\hline Married Women & 140 & 41.09 \\
\hline Unmarried Women & 16 & 4.65 \\
\hline Others (School Girls and Boys) & 4 & 1.16 \\
\hline \multicolumn{3}{|l|}{ Factors for choosing family planning method } \\
\hline Availability & 144 & 42.26 \\
\hline Cost & 30 & 8.68 \\
\hline Effectiveness & 39 & 11.32 \\
\hline Safety & 84 & 24.53 \\
\hline $\begin{array}{l}\text { Others (Secrecy, Route of Administration, Side } \\
\text { Effects, Duration of Use) }\end{array}$ & 45 & 13.21 \\
\hline \multicolumn{3}{|l|}{ Side effect of family planning } \\
\hline Dizziness & 19 & 5.49 \\
\hline Headache & 44 & 12.82 \\
\hline Much Bleeding & 214 & 62.71 \\
\hline Weight Gain & 24 & 6.96 \\
\hline $\begin{array}{l}\text { Others (Nausea \& Vomiting, Breast Tenderness, } \\
\text { Future infertility) }\end{array}$ & 41 & 12.02 \\
\hline
\end{tabular}

Results in Table 2 indicated that majority $301(88.00 \%)$ of the women of reproductive age in Nimule Payam ever heard about family planning, while $41(12.00 \%)$ of the respondents never heard about family planning. The main source of family planning information were 232 $(61.70 \%)$ health center and $52(13.83 \%)$ outreach workers. $25(6.65 \%)$ media and $10(2.66 \%)$ other sources such as places of worships and group meetings were among the least sources of family planning information. The study revealed that $178(22.82 \%)$ oral pills, $151(19.36 \%)$ injecta-plan, $145(18.59 \%)$ condoms and $100(12.82 \%)$ implants were the most known family planning method as opposed to, 61 (7.82\%) Intra Uterine Device (IUD), 61 (7.82\%) lactational amenorrhea, $45(5.77 \%)$ withdrawal and $39(5.00 \%)$ sterilization. The results also revealed that $164(46.59 \%)$ prevention of pregnancy was the most important reason for using family planning method among women of reproductive age in Nimule Payam. Other reasons included 
the $118(33.52 \%)$ prevention of Sexual Transmitted Infections and 46 (13.07\%) and child spacing in the order of importance. Most $229(67 \%)$ of the respondents viewed both male and female as being responsible for family planning while, $110(32.00 \%)$ of the respondents believed women alone were responsible for family planning. Half $182(53.10 \%)$ of the respondents agreed that the main users of the family planning method were sexually active men and women while $140(41.09 \%)$ respondents indicated that the users of family planning were married women.

The results from the study showed that 144 (42.26\%), 84 (24.53\%), 39 (11.32\%) and 30 $(8.68 \%)$ of the respondents indicated the factors determining the choice of their family planning mothed as availability, safety, effectiveness and cost, respectively. Other reasons such as secrecy of the method, route of administration, side effects and duration were mentioned by 45 $(13.21 \%)$ of the respondents. Close to half $144(42.26 \%)$ of the respondents rated availability and $84(24.53 \%)$ safety as the main determining factor for their choice of family planning method while, $30(8.68 \%)$ cost was among the least important determinants. Majority 214 $(62.71 \%)$ of the women of reproductive age in Nimule Payam identified much bleeding and 44 $(12.82 \%)$ headaches as the main side effects of family planning among women of reproductive age in Nimule Payam.

\subsubsection{Overall Knowledge score of the respondents on family planning method}

The overall knowledge levels of the respondents were obtained by ranking their responses to the 10-family planning-related questions in Table 4 . A correct answer was given a score of 1 while a wrong answer was given a score of zero. Respondents who provided 7 and above correct answers to the family planning related questions were rated to have good knowledge of family planning methods. Those who provided 6 or lower correct answers to the family planning related questions were regarded to have less knowledge on family planning methods. The results on the rating of the overall knowledge levels of the women of reproductive age on family planning methods in Nimule Payam is presented in Figure 1.

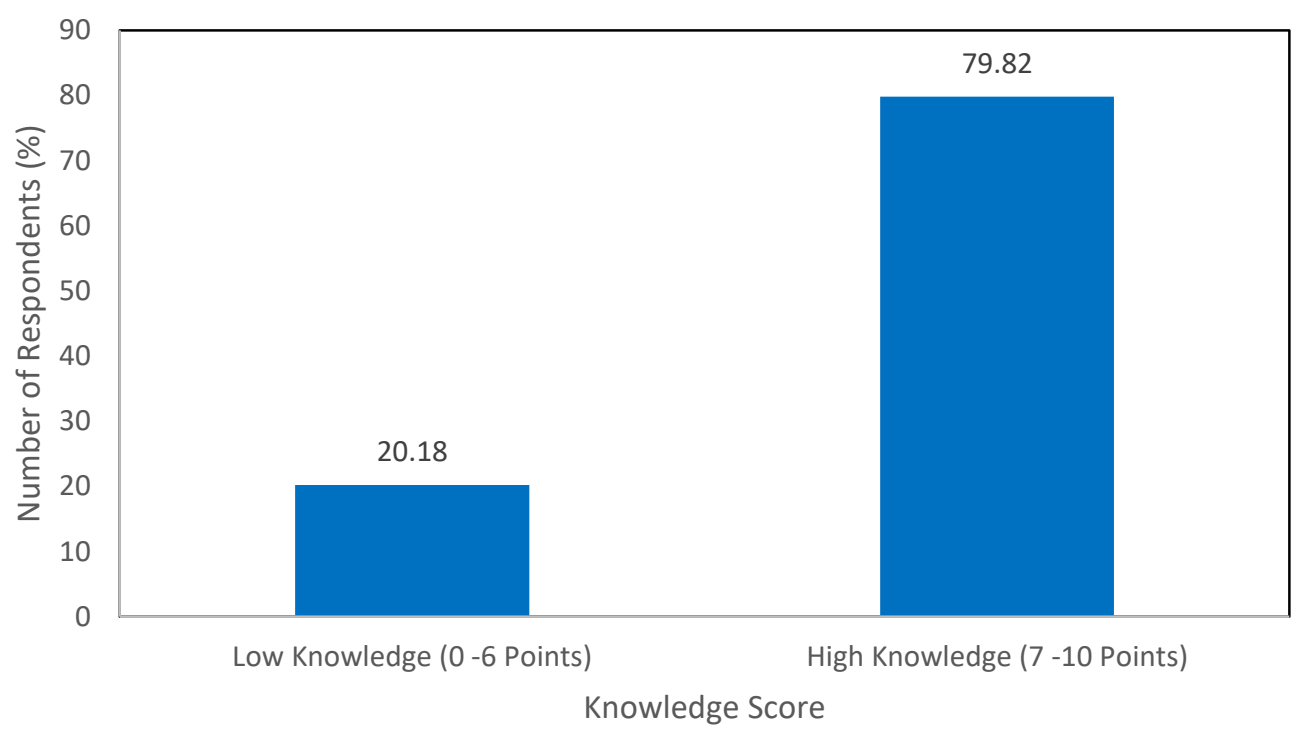

Figure 1. Knowledge levels of respondents on family planning in Nimule Payam.

Results from figure 1 shows that $273(79.82 \%)$ of the respondents had a good knowledge of family planning methods while, $69(20.18 \%)$ had a low level of family planning knowledge. 
International Journal of Health, Medicine and Nursing Practice ISSN 2710-1150 (Online)

Vol.3, Issue No.4, pp $25-41,2021$

www.carijournals.org

The result implies that majority of the women of reproductive age in Nimule Payam had a high level of family planning knowledge.

\subsection{Attitudes of the respondents towards family planning}

The attitude of the respondents on family planning methods was obtained by rating their responses on a 4-Likert scale where: Strongly Agreed (SA), Agreed (D), Disagreed (D) and Strongly Disagreed (SD). The extents to which the respondents agreed or disagreed with the family planning related statements were presented in the Table 3.

Table 3. Attitude of the respondents towards family planning methods in Nimule Payam $(n=342)$

\begin{tabular}{|l|l|l|l|l|}
\hline Questions/Statement & $\begin{array}{l}\text { Strongly } \\
\text { Agree } \\
\mathbf{n}(\%)\end{array}$ & $\begin{array}{l}\text { Agreed } \\
\mathbf{n}(\%)\end{array}$ & $\begin{array}{l}\text { Disagreed } \\
\mathbf{n}(\%)\end{array}$ & $\begin{array}{l}\text { Strongly } \\
\text { Disagreed n } \\
(\%)\end{array}$ \\
\hline $\begin{array}{l}\text { Family planning (FP) is safe to } \\
\text { use }\end{array}$ & $140(40.96)$ & $\begin{array}{l}130 \\
(38.01)\end{array}$ & $33(9.59)$ & $39(11.44)$ \\
\hline $\begin{array}{l}\text { FP can prevent unexpected } \\
\text { pregnancy }\end{array}$ & $194(56.57)$ & $125(36.5)$ & $17(5.11)$ & $6(1.82)$ \\
\hline FP can cause infertility & $28(8.00)$ & $62(18.18)$ & $175(51.27)$ & $77(22.55)$ \\
\hline FP can cause cancer & $36(10.62)$ & $42(12.45)$ & $92(26.74)$ & $172(50.19)$ \\
\hline FP is against God/Allah & $220(64.34)$ & $48(13.97)$ & $40(11.76)$ & $34(9.93)$ \\
\hline FP can cause future abortion & $45(13.14)$ & $46(13.50)$ & $116(33.94)$ & $135(39.42)$ \\
\hline Partner supports FP & $41(12.09)$ & $\begin{array}{l}113 \\
(32.97)\end{array}$ & $112(32.60)$ & $76(22.34)$ \\
\hline FP is against culture & $159(46.52)$ & $70(20.51)$ & $60(17.58)$ & $53(15.38)$ \\
\hline Willing to use FP methods & $131(38.35)$ & $68(19.92)$ & $93(27.07)$ & $50(14.66)$ \\
\hline Encourage others to use FP & $71(20.88)$ & $\begin{array}{l}135 \\
(39.56)\end{array}$ & $87(25.27)$ & $49(14.29)$ \\
\hline $\begin{array}{l}\text { FP has negative effect on } \\
\text { Women }\end{array}$ & $62(18.22)$ & $\begin{array}{l}101 \\
(29.37)\end{array}$ & $89(26.02)$ & $90(26.39)$ \\
\hline
\end{tabular}

The study findings in Table 3 indicated that Majority 270 (78.97\%) of the women of reproductive age in Nimule Payam agreed that family planning was safe to use and 319 (93.07\%) can prevent unwanted pregnancy. Half 179 (52.41\%) of the respondents agreed that family planning has no negative effect on women's health. Majority $252(73.82 \%)$ of the respondents disagreed with the statement that family planning can cause infertility in women of reproductive age, $264(76.93 \%)$ can cause cancer and $251(73.36 \%)$ can cause future abortion. Less than half $154(45.06 \%)$ of the partners of women of reproductive age in Nimule Payam supported family planning while, the majority 188 (54.94\%) did not support family planning. The study revealed that majority $268(78.31 \%)$ of the women of reproductive age in Nimule Payam agreed that family planning was against God/Allah and 229 (67.03\%) their culture.Most 199 (58.27\%) of the respondents agreed that they were willing to use and also $206(60.44 \%)$ encourage others to use family planning methods.

\subsection{Practice of family planning}

Table 4 presents the practice of family planning methods among women of reproductive age in Nimule Payam. 
International Journal of Health, Medicine and Nursing Practice ISSN 2710-1150 (Online)

Vol.3, Issue No.4, pp 25 - 41, 2021

www.carijournals.org

Table 4. Practice of family planning methods among respondents in Nimule Payam $(\mathbf{n}=342)$

\begin{tabular}{|c|c|c|}
\hline Questions/Comments & Frequency & Percentage (\%) \\
\hline \multicolumn{3}{|l|}{ Using family planning $(n=342)$} \\
\hline Yes & 233 & 68 \\
\hline No & 109 & 32 \\
\hline \multicolumn{3}{|l|}{ Family planning method used $(n=233)$} \\
\hline Condom & 88 & 37.7 \\
\hline Implant & 49 & 20.94 \\
\hline Injecta plan & 46 & 19.9 \\
\hline IUD & 4 & 1.57 \\
\hline Oral Pills & 29 & 12.57 \\
\hline Others (vasectomy, tubal ligation, withdrawal) & 17 & 7.33 \\
\hline \multicolumn{3}{|l|}{ How long have you been using? $(n=233)$} \\
\hline$<1$ Year & 97 & 41.75 \\
\hline $1-5$ Years & 116 & 50 \\
\hline $6-10$ Years & 16 & 6.7 \\
\hline$>10$ Years & 4 & 1.55 \\
\hline \multicolumn{3}{|l|}{$\begin{array}{l}\text { Reason for the family planning method used } \\
(n=233)\end{array}$} \\
\hline Accessible & 78 & 33.52 \\
\hline Effective & 19 & 8.24 \\
\hline Fewer Side Effects & 22 & 9.34 \\
\hline Less Costly & 54 & 23.08 \\
\hline Safe & 60 & 25.82 \\
\hline \multicolumn{3}{|l|}{ Did you try other methods? $(n=233)$} \\
\hline Yes & 84 & 36 \\
\hline No & 149 & 64 \\
\hline \multicolumn{3}{|l|}{$\begin{array}{l}\text { Reason for change of family planning method } \\
(n=84)\end{array}$} \\
\hline Bad Side Effect & 42 & 50 \\
\hline Cost & 15 & 18 \\
\hline Others & 27 & 32 \\
\hline \multicolumn{3}{|l|}{$\begin{array}{l}\text { Do you intend to start using family planning? } \\
(\mathrm{n}=109)\end{array}$} \\
\hline Yes & 59 & 54 \\
\hline No & 50 & 46 \\
\hline \multicolumn{3}{|l|}{$\begin{array}{l}\text { Do you go together with your partner for family } \\
\text { planning? }(n=233)\end{array}$} \\
\hline Yes & 77 & 33 \\
\hline No & 156 & 67 \\
\hline
\end{tabular}


International Journal of Health, Medicine and Nursing Practice ISSN 2710-1150 (Online)

Vol.3, Issue No.4, pp 25 - 41, 2021

www.carijournals.org

\begin{tabular}{|l|c|c|}
\hline $\begin{array}{l}\text { Why did you go alone for family planning? } \\
\text { (n=156) }\end{array}$ & & \\
\hline Don't Know & 59 & 25.4 \\
\hline Not Aware & 30 & 12.7 \\
\hline Partner Not Interested & 47 & 41.8 \\
\hline Not Staying together & & 20.11 \\
\hline $\begin{array}{l}\text { Have you ever used but stopped using } \\
\text { contraceptives? (n=233) }\end{array}$ & 84 & \\
\hline Yes & 149 & 36 \\
\hline No & 24 & 64 \\
\hline Why did you stop using contraceptives? (n=84) & 31 & 28.29 \\
\hline Need to Give Birth & 6 & 36.84 \\
\hline Spousal Disagreement & 23 & 7.24 \\
\hline Bad Side Effect & & 27.63 \\
\hline $\begin{array}{l}\text { Others (Cost, Married, Peer Pressure, Myths, } \\
\text { Culture, Religion) }\end{array}$ & & \\
\hline
\end{tabular}

Results in Table 6 showed that majority $233(68 \%)$ of the respondents were using the family planning method. $88(37.70 \%)$ condoms, $49(20.94 \%)$ implants, $46(19.90 \%)$ injecta plan and $29(12.57 \%)$ orals pills were the most used family planning method among the respondents (233). Other family planning method $17(7.33 \%)$ such as Vasectomy, tubal ligation and withdrawal and $4(1.57 \%)$ Intra Uterine Device (IUD) were the least used family planning method among women of reproductive age who were practicing family planning (233) in Nimule Payam. Half $116(50 \%)$ of the users (233) of family planning practiced for $1-5$ years while, a good number $97(41.75 \%)$ practiced for less than a year. The key factors determining the choice of family planning method among the users (233) in Nimule Payam were 78 (33.52\%) accessibility, 60 (25.82\%) safety, 54 (23.08\%) cost, 19 (8.24\%) effectiveness and 22 $(9.34 \%)$ side effect in the order of decreasing importance. Majority 149 (64\%) of the current users (233) of family planning never tried other family planning methods. The study revealed that half $42(50 \%)$ of the 84 respondents who tried new family planning methods were due to bad side effects and 15 (18\%) cost, while 27 (32\%) gave other reasons such as limited supply, previous failure, better options and need for secrecy.

Majority $156(67 \%)$ of the users (233) of family planning attend the services alone. The main reasons for attending family planning services alone among the women included $97(41.80 \%)$ lack of interest from partners, $47(20.11 \%)$ some women were staying alone and $30(12.70 \%)$ not aware that both partners should attend. Few 84 (36\%) users (233) of family planning stopped using the service, while majority 149 (64\%) continued. It was found that majority 31 (36.84\%) of the 84 respondents who stopped using family planning cited spousal disagreement as to the reason while $24(28.29 \%)$ indicated a desire to give birth, $6(7.24 \%)$ side effects of the method and 23 (27.63\%) other reasons that included cost, being married, peer pressure, Myths, culture and religion. The study also revealed that about half $59(54 \%)$ of the 109 respondents who were not using any family planning method did not intend to start using family planning. 
International Journal of Health, Medicine and Nursing Practice ISSN 2710-1150 (Online)

Vol.3, Issue No.4, pp 25-41, 2021

www.carijournals.org

\subsection{DISCUSSION, CONCLUSIONS AND RECOMMENDATIONS \\ 4.1 Discussion of the study findings \\ 4.1.1 Knowledge of the respondents on family planning}

Women of reproductive age in Nimule Payam had high 273 (79.82\%) overall family planning knowledge. Also, majority $301(88.00 \%)$ of the respondents ever heard about family planning methods. Similar levels of awareness on family planning of $89 \%, 87 \%$ and $98.1 \%$ were obtained by Apanga and Adam (2015), Handady et al (2015) and Alege et al. (2016), respectively. The high level of family planning knowledge among women of reproductive age in Nimule Payam can be attributed to the family planning education and outreach programs conducted by Non-Governmental Organizations (NGOs) in partnership with the Ministry of Health as found in similar study by Alege et al. (2016).

The study found that $232(61.7 \%)$ health care workers and $52(13.83 \%)$ outreach workers were the main source of family planning information for women of reproductive age in Nimule Payam as opposed to $14(3.72 \%)$ media, 43(11.44\%) friends and $10(2.66 \%)$ other sources such as places of worship and group meetings. A study by Kasa et al. (2018) in Ethiopia, Handady et al (2015) in Sudan and Alege et al (2016) in Uganda also found that health workers were also the main source of family planning information. In contrast, a study by Mahadeen et al. (2012) in Jordan found that Television (media) was the main source of family planning information followed by health workers. Nimule Payam has limited media coverage and religious institutions do not support family planning practices. This explains why media and religious institutions were not among the main source of family planning information.

The study also showed that short-term family planning methods such as; $178(22.82 \%)$ Oral pills, 151 (19.36\%) Injecta plan and 145 (18.59\%) condoms were the most known in Nimule. Similar results were also reported among women of reproductive age in Uganda (Alege et al., 2016) and Jordan (Mahadeen et al., 2012). This was because these family methods were readily available in Nimule hospital and private clinics. Condoms were also available at public places such as lodges and community condom dispensing points in addition to those distributed by NGOs dealing in reproductive health. The majority 229 (67\%) of the women of reproductive age agreed that both males and females were responsible for family planning. A good number $110(32.00 \%)$ of the respondents believed women alone were responsible for family planning. Also, the majority $182(53.10 \%)$ of the respondents knew that married men and women were the main users of the family planning method, while nearly half 140 (41.09\%) indicated married women as the main users of the family planning method. This could be attributed to the fact that most family planning interventions in the past mainly targeted women as men remained generally sidelined (Aliyu, 2018; Eqtait \& Abushaikha, 2019). This also reinforces the findings in other study were men viewed family planning as women business (Eqtait \& Abushaikha, 2019).

The women also revealed that $144(42.26 \%)$ availability, $84(24.53 \%)$ safety and $39(11.32 \%)$ effectiveness were the main determinant for the choice of family planning method as opposed to cost. This is because family planning inputs were freely provided by NGOs in partnership with the government at Nimule Hospital. The study concurred with the findings of Sensoy et al. (2018) who revealed that accessibility was an important factor for the choice and continued use of particular family planning method among women of reproductive age. While, much bleeding $214(62.71 \%)$ and $44(12.82 \%)$ headaches were the main reported side effects of family planning among women of reproductive age in Nimule Payam. This finding concurred 
with a study by Kasa et al. (2018) identified heavy bleeding as the main side effect of family planning methods among women of reproductive age in Ethiopia.

\subsubsection{Attitude of the respondents toward family planning}

The results from the study revealed a positive attitude towards family planning among women of reproductive age in Nimule Payam. Recent studies also indicated that women in South Sudan have started embracing family planning (Kane et al., 2016; Obwoya et al., 2018). This could be associated with the increased awareness on family planning by the NGOs. Kane et al. (2016) and Obwoya et al. (2018) also attributed the change in the attitude of women of South Sudan due to suffering associated with big family sizes during the decades of civil war and increasing costs of raising children.

However, the study also revealed that the majority 188 (54.94\%) of the partners of the women of reproductive age in Nimule Payam do not support the use of the family planning method. The study findings indicated that family planning was against their 268 (78.31\%) God/Allah and $229(67.03 \%)$ culture. In agreement, Handady et al. (2015) found that religion contributed to negative attitude towards family planning methods among women of reproductive age in Khartoum, Sudan. While, cultural practices have been cited by Kane et al. (2016) as a major hinderance to family planning among the Fertit communities in South Sudan. This was associated with the fact that family planning decisions were mainly made by men. In addition, the cultural practices in South Sudan promotes women to have as many children as possible. The Christians and Muslim religion found in Nimule Payam also views family planning practices as killing of human beings which is against their belief.

\subsubsection{Practice of family planning methods among the respondents}

The study established that most $233(68 \%)$ of the respondents $(n=342)$ were using the family planning method as compared to $109(32 \%)$ of the respondents. The finding on the practice of family planning in Nimule Payam is within the range for the East African region (Kasa et al., 2018; Alege et al., 2016; Handady et al., 2015). However, the practice of family planning found in this study was higher than the $36 \%$ reported in Juba City (Obwoya et al., 2018). The high practice of family planning among women of reproductive age in Nimule Payam can be explained by the high level of awareness and free family planning inputs provided by NGOs in partnership with the government at Nimule hospital. Provision of free family planning inputs has removed cost which is a major barrier to family planning in sub-Saharan Africa (Muanda et al., 2016). Also, being at the border, there was influx of women with family planning information from the neighboring countries. The high prevalence of contraceptive use in a predominantly Christian population may be attributed to shift in decision making that results from sufferings experienced by households with large families during the decades of civil war (Obwoya et al., 2018).

The study finding indicated that condoms, 49 (20.94\%) implants, $46(19.90 \%)$ injecta plan and $29(12.57 \%)$ oral pills were the most used family planning method as opposed to $4(1.57 \%)$ IUD and $17(7.33 \%)$ other family planning methods such as vasectomy, tubal ligation and withdrawal. This study findings agreed with Alege et al. (2016) who studied knowledge, sources and use of family planning methods among women of reproductive age in Uganda. This could be attributed to the temporary effects and free availability of the family planning inputs such as condoms, oral pills and injecta plan at Nimule hospital. Condoms, oral pills, injecta plan and implants are also readily available at friendly costs in private clinics within the Nimule Payam. Oral pills and injecta-plan also provide the secrecy required for women whose 
husbands don't support family planning (Aliyu, 2018). The use of injectable contraceptives also provides the advantages of no user error and less dependence on the women's compliance (Aliyu, 2018).

The results showed that $78(33.52 \%)$ accessibility and $60(25.82 \%)$ safety were the main determining factor for the choice of family planning method among women of reproductive age in Nimule Payam as opposed to other factors such as cost and effectiveness. The study concurred with the findings of Sensoy et al. (2018) and Aliyu (2018) revealed that accessibility was an important factor for the choice and continued use of particular family planning method among women of reproductive age. This is because some bomas such as Jalei are located about $6 \mathrm{~km}$ away from Nimule Hospital. The distance therefore became a barrier for access to family planning services among some women of reproductive age in Nimule Payam. Cost of family planning inputs are not the main determinant because the inputs were freely available at the Nimule hospital. However, cost of family planning inputs still remains the main barrier to the use of family planning service in developing countries, South Sudan inclusive (Aliyu, 2018).

The results indicated that majority 149 (64\%) of the users (233) of family planning never tried any other family planning method. A study by Schwandt et al. (2021) in Rwanda found that the persistent use of a single type of family planning method was an indication that the users have acquainted themselves with the mode of action of the contraceptives and also accepted to live with the resultant side effect. The study also revealed that side effects of the family planning methods was the main reason for switching of family planning method among women of reproductive age. It was established that $84(36 \%)$ of the respondents (233) who were practicing family planning have stopped using the service mainly due to 31 (36.84\%) spousal disagreement. Spousal disagreement has been reported as a major obstacle to family planning in other parts of South Sudan (Kane et al 2016; Obwoya et al 2015), Ghana (Apanga \& Adams, 2015 ) and Uganda (Alege et al., 2016). This could partly explain why majority $156(67 \%)$ of women of reproductive age who were practicing family planning goes for the service alone. This study shows that women are increasingly making family planning decision alone. Also, since majority of the women goes for family planning alone, the practice usually dies as soon as the man discovers it. Women practicing family planning without the consent of their husbands has also been a source of domestic violence in South Sudan which is a conservative patriarchal society (Muanda et al 2016). The lack of support from partners could possibly explain the short duration of use of family planning methods and lack of intent among the current non-users to start using any family planning method.

\subsection{Conclusion}

This study was aimed at assessing the family planning knowledge, attitude and practice among women of reproductive age in Nimule Payam, South Sudan. The following conclusions were drawn from the study.

- Awareness on family planning in Nimule Payam done at Nimule Hospital and through outreach programs has contributed to high family planning knowledge among women of reproductive age in Nimule Payam.

- The women of reproductive age in Nimule Payam had a generally positive attitude toward family planning method. However, culture and religion contributed to negative attitude towards family planning in Nimule Payam. 
- Provision of free family planning inputs at Nimule Hospital has resulted into increase practice of family planning methods among women of reproductive age in Nimule Payam.

\subsection{Recommendations}

Based on the outcome of this study, the following recommendations were made.

- To perfect the knowledge level to a universal state, Health care workers at Nimule hospital and Village Health Teams should continue with awareness on Family Planning Methods as they were the main source of family planning information among women of reproductive age in Nimule Payam. However, other channels of information both formal (such as media) and informal (such as peer to peer) should be explored to reach non-users of family planning.

- Spousal disagreement which was one of the main reasons for discontinuing the practice of family planning practice among women of reproductive age in Nimule Payam should be addressed by developing deliberate strategies that targets the involvement of men in family planning. This may include making it compulsory for men to attend certain health services such as antenatal together with their spouses.

- Stakeholder engagement in support of family planning, community sensitization and provision of diversified family planning inputs at Nimule hospital will be key to improving respondents' attitude and practice of family planning. Church leaders, cultural leaders and community leaders needed to be trained to become champions of family planning methods to address the myth among the respondents that family planning methods were against God/Allah and their culture.

- Accessibility to family planning inputs especially for far bomas like Jalei has to be improved.

- Future study should focus on the factors influencing the Knowledge, Attitude and Practice of family planning methods among women of reproductive age in Nimule Payam.

\section{REFERENCES}

Alege, S. G., Matovu, J. K. B., Ssensalire, S., \& Nabiwemba, E. (2016). Knowledge, sources and use of family planning methods among women aged 15-49 years in Uganda: A crosssectional study. Pan African Medical Journal, 24(39), 1-12. https://doi.org/10.11604/pamj.2016.24.39.5836

Aliyu, A. A. (2018). Family Planning Services in Africa: The Successes and Challenges. Family Planning, 69-88. https://doi.org/10.5772/intechopen.72224

Apanga, P. A., \& Adam, M. A. (2015). Factors influencing the uptake of family planning services in the Talensi district, Ghana. Pan African Medical Journal, 20(10), 1-9. https://doi.org/10.11604/pamj.2015.20.10.5301

Armitage, D., Arends, J., Barlow, N. L., Closs, A., Cloutis, G. A., Cowley, M., Davis, C., Dunlop, S. D., Ganowski, S., Hings, C., Rotich, L. C., Schang, K., \& Tsuji, S. (2019). Applying a " theory of change " process to facilitate transdisciplinary sustainability education. Ecology and Society, 24(3), 1-13. https://doi.org/https://doi.org/10.5751/ES11121-240320

de Silva, M. J., Breuer, E., Lee, L., Asher, L., Chowdhary, N., Lund, C., \& Patel, V. (2014). Theory of Change: A theory-driven approach to enhance the Medical Research Council's framework for complex interventions. Trials, 15(1). https://doi.org/10.1186/1745-6215- 
International Journal of Health, Medicine and Nursing Practice ISSN 2710-1150 (Online)

Vol.3, Issue No.4, pp $25-41,2021$

www.carijournals.org

\section{$15-267$}

de Silva, M., Lee, L., \& Ryan, G. (2015). Using Theory of Change in the development, implementation and evaluation of complex health interventions: A practical guide. Geneva, Swizerland. Mental Health Innovation Network. https://www.mhinnovation.net/sites/default/files/downloads/resource/MHIN ToC guidelines_May_2015.pdf

Government of Southern Sudan [GOSS]. (2011). The transitional constitution of the Republic of South Sudan, 2011. Juba, South Sudan.

Hamed, Z. F., EL-Gazzar, A. F., \& Moftah, F. M. (2018). Knowledge, attitude and practice of family planning methods among husbands in a village of Assiut Governorate. The Egyptian Journal of Hospital Medicine, 73(4), 6489-6493. https://doi.org/10.21608/ejhm.2018.15115

Heil, S. H., Melbostad, H. S., \& Rey, C. N. (2019). Innovative approaches to reduce unintended pregnancy and improve access to contraception among women who use opioids. Preventive Medicine, 128, 1-12. https://doi.org/10.1016/j.ypmed.2019.105794

Kane, S., Kok, M., Rial, M., Matere, A., Dieleman, M., \& Broerse, J. E. (2016). Social norms and family planning decisions in South Sudan. BMC Public Health, 16, 1-12. https://doi.org/10.1186/s12889-016-3839-6

Kasa, A. S., Tarekegn, M., \& Embiale, N. (2018). Knowledge, attitude and practice towards family planning among reproductive age women in a resource limited settings of Northwest Ethiopia. BMC Research Notes, 11, 1-6. https://doi.org/10.1186/s13104-0183689-7

Kassa, M., Abajobir, A. A., \& Gedefaw, M. (2014). Level of male involvement and associated factors in family planning services utilization among married men in Debremarkos town, Northwest Ethiopia. BMC International Health and Human Rights, 14(1), 1-8. https://doi.org/10.1186/s12914-014-0033-8

Leslie, K. (1965). Survey Sampling. New York,NY. John Wiley and Sons.

Mahadeen, A. I., Khalil, A. O., Hamdan-Mansour, A. M., Sato, T., \& Imoto, A. (2012). Knowledge, attitudes and practices towards family planning among women in the rural southern region of Jordan. Eastern Mediterranean Health Journal, 18(6), 567-572. https://doi.org/10.26719/2012.18.6.567

Muanda, M., Ndongo, P. G., Taub, L. D., \& Bertrand, J. T. (2016). Barriers to modern contraceptive use in Kinshasa, DRC. PLoS ONE, 11(12), 1-13. https://doi.org/10.1371/journal.pone.0167560

Mugo, N., Zwi, A. B., Botfield, J. R., \& Steiner, C. (2015). Maternal and child health in South Sudan: Priorities for the post-2015 agenda. SAGE Open, 5(2), 1-14. https://doi.org/10.1177/2158244015581190

Naidu, S. L., Heller, G. Z., Koroi, S., Deakin, L., \& Gyaneshwar, R. (2017). Knowledge, attitude, practice and barriers regarding safe sex and contraceptive use in rural women in Fiji. Pacific Journal of Reproductive Health, 1(5), 223-231. https://doi.org/10.18313/2017.901

Obwoya, J. G., Wulifan, J. K., \& Kalolo, A. (2018). Factors influencing contraceptives use among women in the Juba City of South Sudan. International Journal of Population Research, 1-7. https://doi.org/10.1155/2018/6381842

Population Reference Bureau. (2019). Family Planning Data Sheet 2019. Washington, DC. https://www.prb.org/wp-content/uploads/2019/03/fp-data-sheet-

2019.pdf\%0Ahttps://www.prb.org/international/geography/south-africa

Reinholz, D. L., \& Andrews, T. C. (2020). Change theory and theory of change: What's the 
difference anyway? International Journal of STEM Education, 7(2), 1-12. https://doi.org/10.1186/s40594-020-0202-3

Sarnquist, J. ., Moyo, P., Stranix-Chibanda, L., Chipato, T., Kang, J. L., \& Maldanado, Y. . (2008). Integrating family planning and prevention of mother to child HIV transmission in Zimbabwe. Bone, 23(1), 1-7. https://doi.org/10.1016/j.contraception.2013.11.003.Integrating

Schwandt, H., Boulware, A., Corey, J., Herrera, A., Hudler, E., Imbabazi, C., King, I., Linus, J., Manzi, I., Merritt, M., Mezier, L., Miller, A., Morris, H., Musemakweli, D., Musekura, U., Mutuyimana, D., Ntakarutimana, C., Patel, N., Scanteianu, A., ... Feinberg, S. (2021). Family planning providers and contraceptive users in Rwanda employ strategies to prevent discontinuation. BMC Women's Health, 21(1), 1-13. https://doi.org/10.1186/s12905-021-01503-1

Sensoy, N., Korkut, Y., Akturan, S., Yilmaz, M., Tuz, C., \& Tuncel, B. (2018). Factors Affecting the attitudes of women toward family planning. Family Planning, 33-50. https://doi.org/10.5772/intechopen.73255

Shelter NFI Cluster South Sudan. (2017). Humanitarian Response Plan 2017: Key figures for Eastern Equatoria State. Juba, South Sudan.

Starbird, E., Norton, M., \& Marcus, R. (2016). Investing in family planning: Key to achieving the sustainable development goals. Global Health Science and Practice, 4(2), 191-210. https://doi.org/10.9745/GHSP-D-15-00374

Tolefac, P. N., Nana, T. N., Yeika, E. V., Awungafac, N. S., Ntsama, Y., \& Njotang, P. N. (2018). Trends and patterns of family planning methods used among women attending family planning clinic in a rural setting in sub-Sahara Africa: The case of Mbalmayo District Hospital, Cameroon. BMC Research Notes, 11(1), 10-14. https://doi.org/10.1186/s13104-018-3658-1

United Nations [UN]. (2015). Trends in Contraceptive Use Worldwide 2015 (ST/ESA/SER.A/349). New York, NY.

United Nations [UN]. (2017). Family Planning 2020 Commitment. New York, NY. https://doi.org/10.18356/9789210043694

USAID. (2018). Linkages Across the Continuum of HIV Services for Key Populations Affected by HIV (LINKAGES ) Project. https://pdf.usaid.gov/pdf_docs/PA00X6M3.pdf

Weiss, C. H. (1995). Nothing as practical as good theory: Exploring theory-based evaluation for comprehensive community initiatives for children and families. In New approaches to evaluating community initiatives. New York, NY. The Aspen Institute. 